\title{
IMPACTS OF FAMILY BUSINESSES ON ECONOMIC STABILITY AND GROWTH - AN OPTIMIZATION APPROACH
}

\author{
Gottfried Haber
}

\author{
Department of Economics, University of Klagenfurt, \\ Universitaetsstrasse 65-67, A-9020 Klagenfurt, Austria \\ gottfried.haber@uni-klu.ac.at
}

\begin{abstract}
Family businesses are an important factor for technological progress and high economic efficiency, determining a significant part of economic strength. At present, inside the European Monetary Union (EMU), there are efforts to reduce public debt to fulfill the criteria imposed by the Stability and Growth Pact (SGP), which are mandatory for members of the Euro zone. Due to these constraints, public expenditure has been cut in several European countries. In this paper, the economic implications for optimal budgetary stabilization under alternative rates of technological change are evaluated for Austria, in order to assess the importance of family businesses for stabilization policy and growth. Copyright (C) 2005 IFAC
\end{abstract}

Keywords: optimization, optimal control, economics, nonlinear system, application.

\section{INTRODUCTION}

Family Businesses are a major factor for economic efficiency and technological progress. Technological change in turn is one of the main sources of increasing welfare and a source of social stability, as it leads to a (theoretical) possibility of redistributing economic output without the need for reducing wealth of any economic subject in the economy ("Pareto" improvement). On the other hand, technological progress influences both the effects and the sustainability of economic policy as it changes reaction patterns of economic aggregates. The presence of a quantitatively and qualitatively important sector of family businesses has significant implications for optimal economic stabilization policy and economic growth. This paper uses an econometric model of the Austrian economy (AMOD1) and the optimization algorithm OPTCON to asses the impacts of different magnitudes of the family business sector for the Austrian economy and for economic stabilization measures.
As in several other European countries, public debt in Austria had been rising during the last three decades until the introduction of the common currency zone in Europe. The peak level of public debt was nearly 70 percent of GDP at the end of the twentieth century, which is significantly above the 60 percent reference value given by the SGP. Only relatively high priority on the debt target might lead to a sustained consolidation of the public sector (Haber, 2001); these results are used to restrict the number of optimization exercises to a so called strong consolidation scenario. Exogenous productivity changes caused by technological progress due to alternative influence of family businesses are imposed on the model. Optimal economic policy is calculated for those different scenarios. In particular, optimal stabilization of public debt is investigated. As previous papers have shown, fiscal consolidation efforts tend to produce significant output losses (welfare losses) in the short-run, but in the long-run even positive effects can be observed. Some results for European monetary policy have been described previously (Neck et al., 2000); this paper 
concentrates on the fiscal policy aspect and the room for fiscal stabilization policy, if the importance of family businesses changes.

\section{MODEL FRAMEWORK}

AMOD1 (Haber, 2000) is an annual econometric model of the Austrian economy, which is well suited for economic policy analyses. The version of the model used in this paper consists of 57 equations, including 29 (stochastic) behavioral equations and 28 definitions. The number of estimated coefficients is 97; in the base version of AMOD1, 13 exogenous variables are included, where four of them may be used as economic policy instruments. AMOD1 is based upon neoclassical assumptions as well as on Keynesian considerations: There are (partly) forward-looking expectations on the one hand and backward-looking rigidities on the other hand. As a result, the model provides a well-defined long-run growth path and disequilibria at the same time. The main sectors are: a twice disaggregated consumption block, the wage-price system, a production sector, the monetary sphere, a foreign trade sector and, the public sector. For all parts of the model, microeconomic foundations and optimizing behavior of the private agents have been applied to derive the specifications of the estimated equations. The highly nonlinear model is estimated in blocks, using iterative three-stage least squares (iterative 3SLS), seemingly unrelated regressions (SUR) and ordinary least squares (OLS). Estimation period is 1976-1998; extensive evaluation and checks of all parameters have been performed (Haber, 2000) and show that the quality of AMOD1 may be compared to other widely used models of the Austrian economy.

Private consumption is determined in a consumption block that is disaggregated twice, in eleven groups of goods (food and beverage, health, housing, etc.) and four types of goods (durables, non-durables, etc.). The specification is compatible with the absolute income hypothesis and the permanent income hypothesis, allowing for Keynesian as well as neoclassical elements. The wage-price system is highly interdependent and comprises the main factors of inflation as well as the specific institutional situation of the Austrian labor market and the characteristics of the wage bargaining process. Inflation may be effected by wage increases, by higher import prices and by high capacity utilization. Nominal wages in turn are determined by the price level, by the level of unemployment and by changes in productivity. Economic agents exhibit partly forward-looking behavior in both determining prices and wages. Labor supply is disaggregated by gender. As a factor of production, labor is treated as a homogenous input. Labor demand is derived from the first order conditions of profit maximization of the firm. The specification of private investment is based upon the concept of the maximization of the market value of the firm, which is compatible with Tobin's marginal $q$ and with the extended accelerator hypothesis.

Potential output $Y$, as derived from equation 1 ( $K$ is the capital stock, $\gamma$ is the natural growth rate of potential GDP and includes technological progress, $A_{0}$ is the constant of the Cobb-Douglas production function, $t$ is a time trend, $L$ is employment, and ( $1-$ $\alpha$ ) is the wage quota), is calculated using an estimated constant elasticity of scale (CES) production function of the Cobb-Douglas type by substituting actual labor demand with the total labor force. For the optimizations here, the coefficient $\gamma$ is modified at the beginning of the optimization period. As the base year for the linear trend $t$ is 1970 and the beginning of the simulations in this paper is 2000, the $\gamma t$ is replaced by equation 2 , where $\beta=\gamma$ and $\delta$ is a productivity offset:

$$
\begin{gathered}
\ln \left(\frac{Y}{K}\right)=A_{0}+\gamma t+(1-\alpha) \ln \left(\frac{L}{K}\right) \\
\gamma t=\beta t+\delta(t-30)
\end{gathered}
$$

Inversion of the real money demand equation yields a nominal short-run interest rate equation, which is estimated directly. The exchange rate peg to Germany (since the beginning of the eighties) enters the model through the historical values of the (effective) exchange rate and money supply. Based upon the short-run interest rate, both a long-run interest rate and an effective interest rate for the public sector are calculated. This accounts for the realistic feature that the interest rate on public debt is different from the interest rates for the private agents, at least in the short-run, and is especially useful for analyses of the public sector.

Exports are mainly determined by the relative competitiveness of domestic production, while imports essentially depend on domestic demand. For the chosen specification, income effects (in the export equation) and price effects (in the import equation) could be identified as rather small and were therefore dropped. On the foreign goods markets, rigidities are explicitly taken into account. The (nominal effective) exchange rate equation is built around the weak interest rate parity hypothesis (for the determination of the exchange rate), which is a reasonable paradigm in the presence of high capital mobility. For the estimation period, it is assumed, that Austria faces flexible exchange rates to the rest of the world (except Germany and some other countries implementing an exchange rate peg to Germany). 
Optimum control of economic systems can be used for evaluating economic policy and to find "optimal" values for the economic instruments. This makes sense, if there are given desired target values for at least some of the endogenous variables (an "ideal situation". Weights have to be attached to the objectives, indicating their relative importance. Thus, an objective function can be specified, for ease of computation generally in the form of an additively separable quadratic welfare loss function, which is minimized subject to the econometric system.

OPTCON (Matulka and Neck, 1992) is an optimization algorithm that is able to deal with both deterministic and stochastic setups (with uncertainty in the parameters and in the residuals) for linear and non-linear problems, which distinguishes OPTCON from other widely used algorithms (Chow, 1975; Chow, 1981, Kendrick, 1981). Due to limitations in previous versions of OPTCON concerning highly non-linear systems of medium to large scale, version $3.0001 \mathrm{~b}$ (Haber, 2000) is used for the (deterministic) optimizations in this paper. In the original version, OPTCON uses a Gauss-Seidel procedure to approximate a deterministic solution of the system. Then, the non-linear system is optimized. This is done starting with the previously calculated approximation by iteratively running a backward recursion and applying Bellman's principle of optimality in order to get the parameters of a policy feedback rule. In a last stage, a forward projection (simulation) of the model is performed. In the version of OPTCON used in this paper, the Gauss-Seidel procedure is replaced by a modified NewtonRaphson algorithm, which tends to be more stable in the presence of extensive non-linearities. For further information refer to the sources mentioned above.

\section{OPTIMIZATION SCENARIOS}

For the experiments in this paper, first a baseline solution of the model is calculated, where the natural growth rate of GDP is kept at the original value of 0.0097 (this is approximately 1 percent). Thus, the offset $\delta$ is zero for the baseline. This simulation gives the desired values for the target variables in the subsequent optimization exercises. Table 1 shows the weights in the linear quadratic welfare loss function, which is imposed in the optimization runs.

The main target is the debt to GDP ratio with a desired value of 60 percent. GDP and private consumption are minor targets of the economic policy maker in the scenarios considered here. Note that the instruments (nominal public consumption, nominal public investment, and the nominal exogenous component of net taxes) are included in the objective function in order to increase the stability of the solution and the smoothness of the implemented optimal policy. The huge differences in the dimensions of the respective weights are given by the relative importance of the respective targets and by differences in the dimensions used for the variables. Apart from the debt to GDP ratio, all target values are taken from the baseline.

Table 1. Weights of the targets in the objective function

\begin{tabular}{lr} 
Variable & \multicolumn{1}{c}{ Weight } \\
\hline Public Debt [ratio to GDP] & $1.000,000.0$ \\
GDP (real) & 1.0 \\
Private consumption (real) & 1.0 \\
Inflation rate & $100,000.0$ \\
Public consumption (nom.) & 0.1 \\
Public investment (nom.) & 0.1 \\
Net taxes, exogenous (nom.) & 0.1 \\
\hline
\end{tabular}

With this setup, three different optimization scenarios are run. Scenario 1 corresponds to the strong consolidation scenario mentioned above (Haber, 2001), without any modifications. Scenario 2 depicts an increase in technological progress due to a larger magnitude of the family businesses in the economy leading to an increase in the natural GDP growth rate by 0.25 percentage points per annum (fast scenario). A reduction of the annual GDP growth rate by 0.25 percentage points is the framework for scenario 3 (slow scenario). The time horizon for all calculations is 2000--2010; in order to ensure model convergence and convergence of the optimum control solutions, more periods (up to the year 2025) were used for some of the calculations, where appropriate.

\section{RESULTS}

The main results of the fiscal consolidation in scenario 1 (reference optimization) are cuts in public expenditure (public consumption and public investment) and increases in net taxes. These measures decrease public debt gradually to the desired level of 60 percent of GDP; fluctuations of the deficit figure are still observable in the optimal time path. This very restrictive strategy of the policy maker leads to losses in output (GDP), lower inflation and a small increase in unemployment (Haber, 2001). Here, the point of interest is the sensitivity of the optimal fiscal consolidation policy with respect to the magnitude of technological progress. Note that most of the figures depicted in the following section represent deviations from the simulated baseline values. The horizontal axis is the time axis. In the legend of the figures, the digits 1--3 represent the calculated scenarios. 


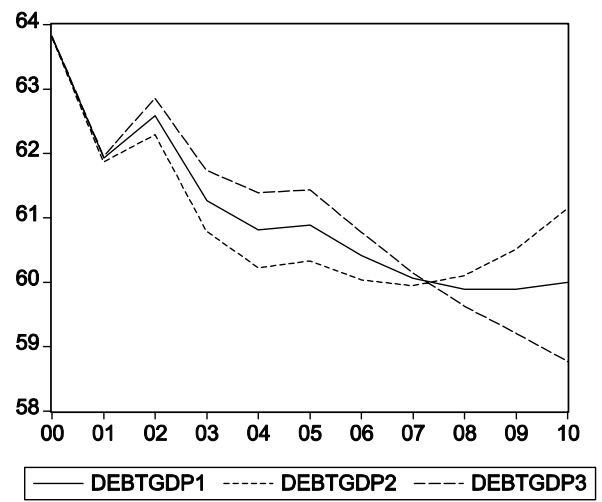

Figure 1. Public debt ratio (level) [percent of GDP]

Figure 1 shows the time paths of the public debt to GDP ratio. In all three cases, the target value is reduced continously (compared to the baseline, which is not given here), which indicates that the main target is followed more or less successfully for all degrees of technological change. Up to the year 2007, faster technological progress implies that the consolidation process can be done more easily. After this period, only the slow scenario (3) is able to reduce the stock of public debt even below the reference value, which of course also has to be seen as suboptimal from the point of the objective function. This result seems counter-intuitive at this stage but cannot be interpreted without looking at the optimal values of the economic policy instruments. As will be shown below, faster technological progress implies that the economic policy measures implemented by the policy maker may be less expansionary or, as in this case, more contractionary. Thus, (nearly) successful fiscal consolidation might be reached earlier, but on the other hand this more intensive consolidation might reduce the stock of capital in the long run compared to the reference optimization (1) and the slow scenario (3), leading to lower GDP. As GDP is the denominator of the debt to GDP ratio target value, this arithmetic might be the solution to this phenomenon, which is of course related to the discussion of Keynesian and nonKeynesian effects of fiscal policy. Additionally, and that might be the main effect, the reductions in inflation and the price level (see below) lead to an increase in debt in real terms. As real GDP cannot be increased beyond potential output in the long run, stabilization of the debt to GDP ratio might become more difficult with subsequent periods. These findings should be investigated in more detail in future analyses.

Figures 2 and 3 show the development of fiscal deficits (the flow variable related to the stock of public debt). In all three scenarios, deficit fluctuations are preserved, leading to smoother results for the debt, private consumption, and GDP targets. Until the year 2009, deficits (as percentages of GDP) are lower for higher degrees of technological progress. In turn, an explanation to this reversal of the three scenarios at the end of the optimization horizon might be based upon the effects on the price level.
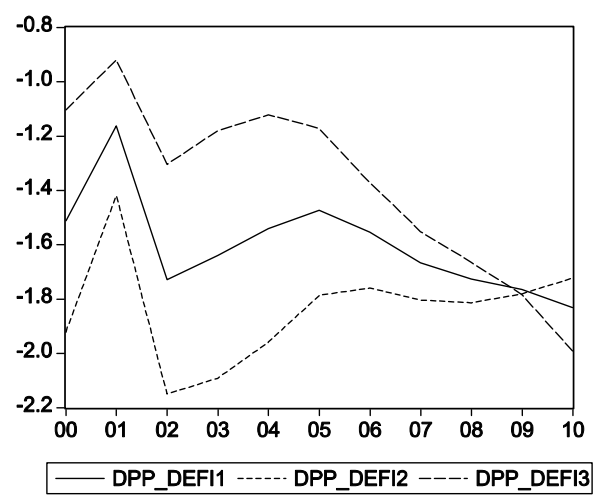

Figure 2. Deficit ratio (deviation) [percentage points]

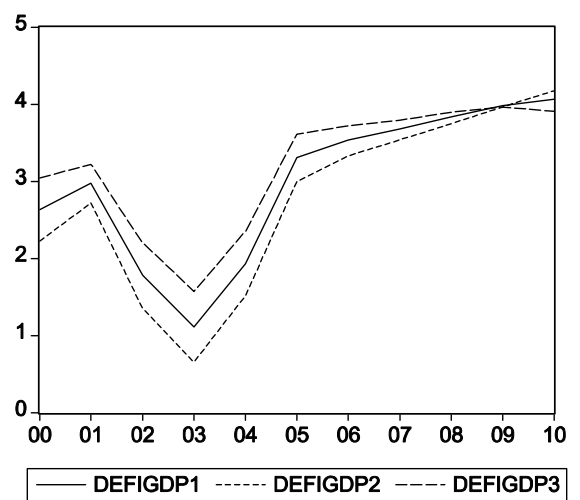

Figure 3. Deficit ratio (level) [percent of GDP]

The optimal values of the policy instruments (nominal public consumption, nominal public investment and nominal exogenous net taxes) show that the optimal policy must be contractionary in order to reach the fiscal target. Public expenditure is reduced significantly, while an increase in net taxes can be observed. As a rule of thumb, higher rates of technological progress lead to more restrictive measures. Again, this result has to be interpreted in the context of the target variable: higher growth rates tend to increase real output and reduce the debt ratio without the need for sharp restrictive policy measures. But on the other hand, higher potential output caused by technological progress increases the output gap (the difference between actual GDP and potential GDP) and tends to lower the price level. This leads to deflation (or lower inflation) and has negative effects on the business sector of the economy. Moreover, the lower price level increases real variables (e.g. public expenditure) ceteris paribus, thus the nominal magnitudes can be reduced without a change in real activity. Put differently, the price effects of higher rates of technological progress lead to more restrictive measures concerning the nominal instruments. 


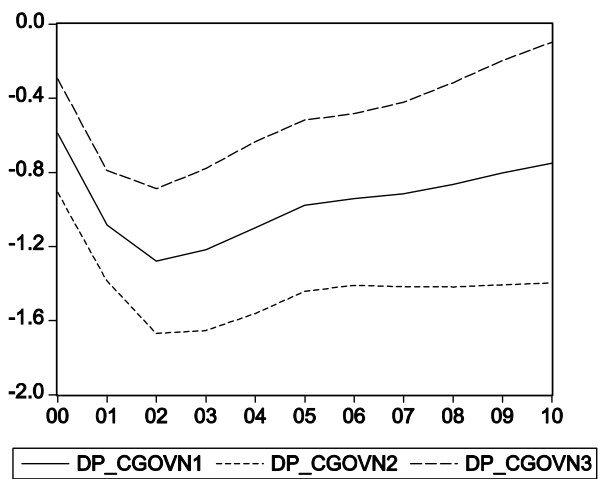

Figure 4. Public consumption [percent of GDP]

Nominal public consumption (Figure 4) is reduced by more than 0.8 percent of GDP in the slow scenario and by more than 1.6 percent of GDP in the fast scenario. In scenario 3 (slow), the instrument nearly returns to the baseline values, while the reduction in public consumption is permanent in the fast scenario and remains about 1.4 percent below the baseline in the long run.

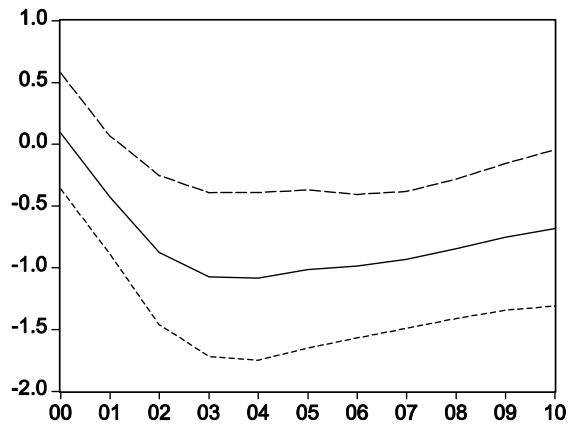

- DP_INVOBN1 -----. DP_INVOBN2 ---- DP_INVOBN3

Figure 5. Public Investment [percent of GDP]

Nominal public investment (as shown in Figure 5) follows a similar time path as public consumption described above. The main difference is that in the first two periods, an increase in public investment can be observed for the slow scenario. This is consistent with theoretical considerations, as a slowdown of technological progress implies higher public activity in research and development. Public investment is lowest in the fast scenario and highest in the slow scenario.

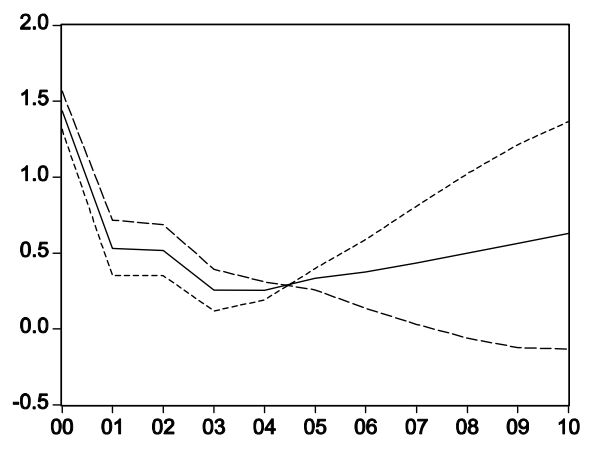

Figure 6. Exogenous net taxes [percent of GDP]
In Figure 6 the time paths for nominal exogenous net taxes are depicted. Taxes are raised by approximately 1.5 percent of GDP in the first period in all three scenarios and then gradually reduced towards the baseline. Taxes are generally slightly higher in the slow scenario until 2004; afterwards significant differences among the time paths can be observed, where taxes are higher in the fast scenario now.

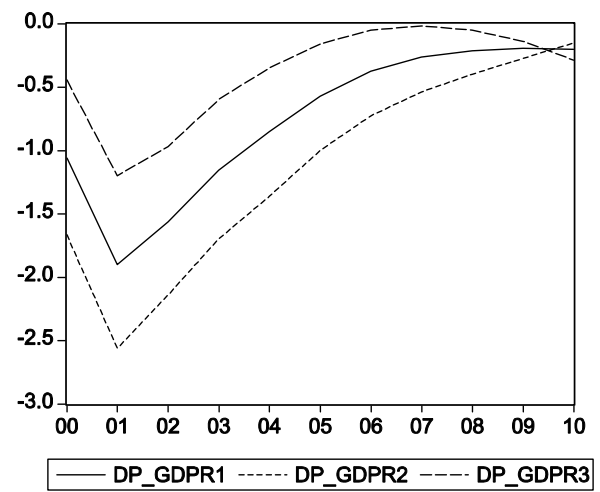

Figure 7. GDP [percent]

The main economic variable is real GDP (Figure 7), describing the real output of the whole economy. GDP assumes rather different values in the three alternative scenarios: While output losses in the short run (maximum in 2001) amount to more than 2.5 percent in the fast scenario, they remain below 1.25 percent in scenario 3. In all three scenarios, output losses diminish gradually in the medium run, with the most preferable values in the slow scenario. At the end of the time horizon, the order of preference changes: Now scenario 2 produces the smallest output losses due to the fiscal consolidation program. Note that the relatively high output losses in 2001 are consistent with the mainstream forecasts for Austrian GDP growth for this period.

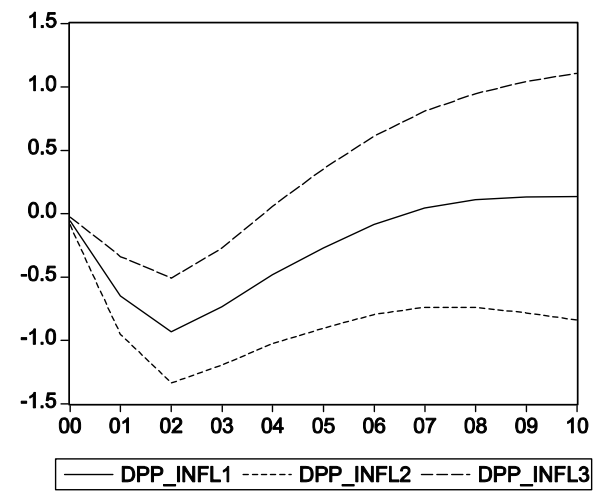

Figure 8. Inflation rate [percentage points]

The high-tech scenario (2) shows inflation rates (Figure 8) well below the baseline of the model (up to 1.4 percentage point lower in the short run and about 1 percentage point lower in the long run). In the reference optimization (scenario 1), the reduction of the inflation rate reaches a maximum of --1 
percentage point; in the long run, inflation returns to the baseline values. In the slow scenario (3), the inflation rate is slightly reduced during the first three periods but rises steadily and consolidates at about 1 percentage point above the baseline. Higher potential output increases the output gap and leads to deflationary effects in the short run. Although the inflation rate is included in the objective function, stabilization of the inflation rate occurs rather slowly, leading to cumulative differences in price levels among the baseline and the three scenarios analyzed here. This causes shifts in the nominal and real magnitudes of several key variables of the economic system and has already been identified as a source of some of the findings above.

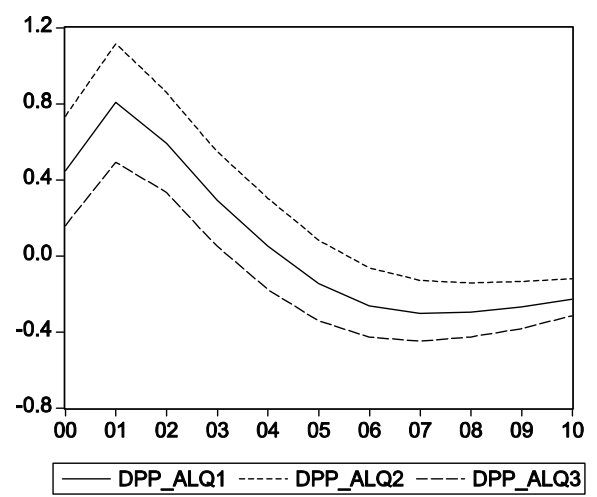

Figure 9. Unemployment rate [percentage points]

In the fast scenario, unemployment (Figure 9) rises by up to 1.1 percentage points above the baseline (year 2001). The peak in the slow scenario is only 0.5 percentage points. This can be attributed to the more restrictive policy measures in the scenario with a higher rate of technological progress, which tend to exhibit strong Keynesian effects in the short run. Note that after 2005, unemployment is below the baseline in all scenarios. This shows that (at least in the long run) employment returns to an equilibrium level, regardless of the specific policy measures taken. On the other hand, in the short run, employment reacts very sensitive to different rates of technological change in a fiscal consolidation framework.

\section{CONCLUSIONS}

For all periods, the reference optimization (scenario 1) produces values of the endogenous variables and of the instruments, which are in between the values of the other scenarios. Thus, the order of the scenarios is consistent for the whole time horizon. The analysis has shown that there are significant differences in the reaction of the economy and in the optimal time paths of the economic policy instruments, if the rate of technological change is altered in the model due to different magnitudes of the family business sector in the economy. Strong effects could be observed originating from changes in inflation and the overall price level, leading to shifts in the framework of nominal and real variables.

It can be summarized that the positive impacts of higher productivity caused by innovation and efficiency in family businesses might lead to different reactions of macroeconomic policy makers if the objective function remains constant. Positive effects might be waived by too sharp reactions of economic policy. Thus economic policy makers should be careful with budgetary consolidation in the presence of higher productivity growth due to restructuring of the economy.

It is worth noting that some of the findings in this paper have not been treated in the economic literature, yet. Of course, the results presented here have to regarded as still preliminary and more extensive work on these issues should be performed. Especially, stronger theoretical foundations of the effects found in this paper and sensitivity analyses should be carried out. Nevertheless, this paper has shown the strong dependency of the specific design and the performance of optimal economic policy on the degree of technological change and the structure of the economic system.

\section{REFERENCES}

Chow G. C. (1975): Analysis and Control of Dynamic Economic Systems. New York et al.

Chow G. C. (1981): Economic Analysis by Control Methods. New York et al.

Haber G. (2000): AMOD1. Ein makroökonometrisches Modell für Österreich. $\mathrm{PhD}$ thesis. Vienna University of Economics and Business Administration. Vienna.

Haber G. (2001): Simulation analysis of public debt and fiscal deficit in Austria - optimal economic policies for the past and the future. Accepted for publication in Empirica.

Kendrick D. (1981): Stochastic Control for Economic Models. New York et al.

Matulka J. and Neck R. (1992): OPTCON: An algorithm for the optimal control of nonlinear stochastic models. In: Annals of Operations Research, 37 (1992), 375-401.

Neck R., Haber G., and McKibbin W. J. (2000). Macroeconomic policy design in the European Union: A numerical game approach. In: Empirica, 26(4), 319-335. 